\title{
Inhibition of Bevacizumab-induced Epithelial-Mesenchymal Transition by BATF2 Overexpression Involves the Suppression of Wnt/ $\beta$-Catenin Signaling in Glioblastoma Cells
}

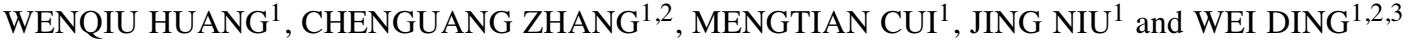 \\ ${ }^{1}$ Department of Biochemistry and Molecular Biology, Capital Medical University, Beijing, P.R. China; \\ ${ }^{2}$ Beijing Key Laboratory for Researches in Cancer Invasion and Metastasis, \\ Cancer Institute of Capital Medical University, Beijing, P.R. China; \\ ${ }^{3}$ Beijing Institute of Brain Disorders, Beijing, P.R. China
}

\begin{abstract}
Background/Aim: Bevacizumab (BV) has been used for the treatment of recurrent glioblastoma. However, it also induces epithelial-mesenchymal transition (EMT) in glioblastoma cells, which compromises its efficacy. BATF2 (basic leucine zipper ATF-like transcription factor 2), a multi-target transcriptional repressor, has been found to suppress cancer development partly through inhibition of $W n t / \beta$-catenin singling. The roles of BATF 2 and Wnt/ $\beta$ catenin signaling in $B V$-induced EMT in glioblastoma cells were investigated in this study. Materials and Methods: BV was used to treat U87MG cells, and TOP/FOP FLASH luciferase reporters were employed to determine the activity of Wnt/ $\beta$-catenin signaling. EMT markers were detected with quantitative reverse transcription-PCR and western blotting. Immunofluorescence $(I F)$ was used to determine the compartmentation of $\beta$-catenin. Wound-healing, TransWell and ECIS assays were used to analyze cell adhesion, invasion and migration. Results: BV induced EMT phenotype in U87MG cells, and BATF2 overexpression significantly inhibited BV-induced EMT with suppression of Wnt/ $\beta$ catenin signaling. Conclusion: Our findings expanded the understanding of the role of BATF2 in tumors, and also suggested a potential of using BATF2 as a therapeutic target to hinder bevacizumab induced EMT in glioblastoma.
\end{abstract}

Glioblastoma (GBM) is the most common and devastating brain cancer that causes a severe global health burden (1). Although the treatment has improved in recent years, the

Correspondence to: Wei Ding, Department of Biochemistry and Molecular Biology, Capital Medical University, Beijing 100069 , P.R. China. Tel: +86 1083950117, Fax: +86 1083911496, e-mail: weiding@ccmu.edu.cn

Key Words: Glioblastoma, BATF2, EMT, Wnt/ $\beta$-catenin. outcomes, as shown by the patient median survival postdiagnosis, remain at just over 14 months (2). In patients with disease recurrence, the survival time can be as short as only 3-9 months (3). Bevacizumab (BV), also known as Avastin, is a targeting drug designed to block vascular endothelial growth factor (VEGF) for the strategy of anti-angiogenic therapies. The results from phase II trials have demonstrated significant benefits of $\mathrm{BV}$ for patients with prolonged, median response durations of 3.9 to 4.2 months (4-6). The US Food and Drug Administration approved bevacizumab for treating adult GBM with progression after prior treatment (recurrent or rGBM) in 2009 (7). However, this antiangiogenic therapy appeared to be failing to translate into a significant overall survival benefit. One of the major causes is due to the unexpected activation of epithelialmesenchymal transition (EMT), which is an event usually occurring, and well-described, in epithelial-derived tumors (8-10). EMT is also increasingly recognized as a key event in non-epithelial cancers for malignant phenotypes, including GBM (8-10). The discovery and recognition of BV-induced EMT has become a critical concern for BV clinical applications (11). Emerging data have suggested that unconventional resistance to anti-angiogenic therapy existed, linking to evasive resistance and intrinsic or pre-existing indifference (12). The molecular mechanisms underpinning the development of EMT following anti-angiogenic therapy is poorly understood, especially in GBM. A recent report demonstrated hypoxia as a key regulator of EMT involving the activation of the transcriptional regulators hypoxiainducible factors HIF- $1 \alpha$ and HIF-2 $\alpha$ (13). In addition, $\mathrm{Wnt} / \beta$-catenin signaling has been critically implicated in EMT of GBM cells upon anti-angiogenic treatment.

The Wnt/ $\beta$-catenin signaling is a highly conserved pathway throughout evolution. The members of the Wnt family of proteins have kept a high homology from drosophila to mammals (14). Wnt signaling pathway plays a crucial role in 
the development of human cancers (15). In certain epithelial tumors, aberrant activation of $\mathrm{Wnt} / \beta$-catenin signaling was believed to be an important requirement for the development of EMT. Therefore, research focusing on the Wnt signaling pathway gradually became an intense area of study in the drug design field. In the canonical Wnt pathway, $\beta$-catenin is the key effector responsible for transduction of the signal to the nucleus. When $\beta$-catenin accumulates in the cytoplasm, it translocates into the nucleus, where it associates with DNAbinding transcription factors of the T-cell factor/lymphoid enhancer factor (TCF/LEF) and then activates transcription of target genes (16).

As a novel tumor suppressor gene, basic leucine zipper ATF-like transcription factor 2 (BATF2) has been found to suppress both cancer growth and migration (17). BATF2 was shown to have promising potential for use as a candidate marker for diagnosis in several tumors, as well as for prognosis (18-20). More importantly, BATF2 was also suggested as an encouraging therapeutic treatment against a wide variety of cancers (21). The mechanism responsible for this tumor inhibitory effect can be complex, involving the suppression of AP-1, NF-kB in the network of transcriptional regulation $(22,23)$. A report also showed that BATF2 overexpression could inhibit angiogenesis through the reduction of VEGF expression (24). Loss of BATF2 expression initiates EMT, which involves the inhibition of the $\mathrm{Wnt} / \beta$-catenin pathway in lung adenocarcinoma cell lines and in clinical lung adenocarcinoma specimens (25). Earlier studies have shown that the anti-tumor activity of BATF2 seemed to be dependent on its interaction with c-Jun (22), which was known to positively correlate with the strength and maintenance of the Wnt signaling. Whether the activation of the Wnt signaling pathway is important for the development of EMT in glioma cells, especially following $\mathrm{BV}$ treatment, and how it relates to the tumor-suppressive effects of BATF2 is largely unknown. In this study, we investigated the role of BATF2 on $\mathrm{Wnt} / \beta$-catenin signaling and its influence in BV-induced EMT in GBM cells.

\section{Materials and Methods}

Cell culture and transfection. U87MG cells were purchased from China Infrastructure of Cell Line Resources (Beijing, P.R.China), and were cultured in Dulbecco's modified Eagle's medium (DMEM) with the supplements of $10 \%$ fetal bovine serum (FBS) and $1 \%$ penicillin and streptomycin. For applying anti-angiogenic agents in glioma cells, bevacizumab (Roche, Paris, France) at 1 100 $\mu \mathrm{g} / \mathrm{ml}$ was added in serum-free medium (26). A BATF2 overexpressing plasmid constructed from a human cDNA library. U87MG cells at 50 70\% confluence were transfected using Lipofectamine $^{\mathrm{TM}} 2000$ (Invitrogen, Carlsbad, CA, USA) following the manufacture's instruction. A change of fresh medium was conducted at exactly $6 \mathrm{~h}$ post transfection. A GFP plasmid was used as a control for determining the transfection efficiency.
Luciferase reported assay for Wnt/ $\beta$ catenin signaling. A TopFLASH containing 3 copies of TCF-4 binding sites and a FopFLASH containing mutated TCF-4 sites was kindly provided by Dr. Xiaowei Zhang of Peking University, Beijing, P.R.China. U87MG cells were seeded into 48-well plates and transfected with $0.1 \mu \mathrm{g}$ TopFLASH or FopFLASH plasmid using Lipofectamine ${ }^{\mathrm{TM}}$ 2000. Twenty-four hours later, the cells were treated with bevacizumab in a concentration range from 1 to $100 \mu \mathrm{g} / \mathrm{ml}$ for 24 $\mathrm{h}$. The luciferase activities were measured at $48 \mathrm{~h}$ with the Luciferase Assay System (Promega, Madison, WI, USA) using a Lumat LB9507 luminometer (Berthold, EG\&G, Wildbad, Germany). All assays were performed in triplicate.

Immunofluorescence microscopy. Following treatment, U87MG cells were fixed with $4 \%$ paraformaldehyde, and then permeabilized with $0.1 \%$ Triton X-100 in 24-well plates. The cells were incubated with the primary antibodies overnight at $4^{\circ} \mathrm{C}$. Antibodies were used as follows: anti $\beta$-catenin, Snail, ZEB or Vimentin (1:50, Santa Cruz,CA, USA); anti-Twist, BATF2 (1:200, Abcam, Cambridge, UK); anti-Flag (1:100, Sigma-Aldrich, St. Louis, USA). Alexa fluor (R) 594 goat A, Alexa fluor (R) 488 goat A (1:500, Invitrogen, NY, USA). Staining of the nuclei was carried out using 4',6-diamidino2-phenylindole (DAPI). Samples were analyzed under a Leica DM5000 B fluorescent microscope and scanned by a Leica SP5 confocal microscope (Leica Microsystems, Wetzlar, Germany).

RNA extraction, RT-PCR and quantitative real time PCR. Total RNAs from U87MG cells were extracted using a RNeasy Mini Kit according to the manufacturer's protocol (QIAGEN, Hilden, Germany). The amount of $1 \mu \mathrm{g}$ of total RNA was transcribed into cDNA using the Reverse Transcription Kits (Takara, Daian, China). The PCR primers for detected genes were shown in Table I. The real-time PCR assays were performed using SYBR Green (TOYOBO CO., Japan) with a Bio-Rad CFX Connect ${ }^{\mathrm{TM}}$ Real-Time PCR Detection System. The reaction parameters were set as (a) $95^{\circ} \mathrm{C}$ for $2 \mathrm{~min}$, (b) $95^{\circ} \mathrm{C}$ for $5 \mathrm{~s}, 58^{\circ} \mathrm{C}$ for $30 \mathrm{~s}$, total 40 cycles (c) $95^{\circ} \mathrm{C}$ for $5 \mathrm{~s}$, (d) Melt Curve $65^{\circ} \mathrm{C}$ to $95^{\circ} \mathrm{C}$, increment $0.5^{\circ} \mathrm{C}$ for $5 \mathrm{~s}$, (e) then $4^{\circ} \mathrm{C}$ hold. $\beta$-actin was used as an internal control. The fold

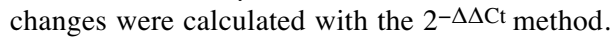

Western blotting. Total proteins were extracted from U87MG cells in culture using the RIPA buffer. The protein concentrations were determined using a bicinchoninic acid (BCA) kit (Merck Millipore, Darmstadt, Germany). A total of $15 \mu \mathrm{g}$ protein per sample was loaded and subjected to separation in a $10 \%$ SDS-PAGE gel, and then transferred onto the polyvinylidene fluoride (PVDF) filters (Merck Millipore). After blocking with the TBST containing 1.5\% BSA, the filters were incubated with the primary antibodies overnight at $4^{\circ} \mathrm{C}$. The antibodies used included anti-Twist (1:2.000, Abcam, Cambridge, UK), anti-BATF2 (1:1000, Abcam, Cambridge, UK), anti- $\beta$-catenin and anti-Snail (1:1000, Santa Cruz, CA, USA), ZEB (1:1000, Santa Cruz, CA, USA), anti-Vimentin (1:1.000, Santa Cruz, CA, USA), Ncadherin or $\beta$-actin $(1: 1,000$, CST, MA, USA). Following incubation with Goat anti-Mouse/Rabbit IgG Secondary Antibody HRP conjugated, Rabbit anti-Goat IgG Secondary Antibody HRP conjugated $(\mathrm{SAB})$ at room temperature for $1 \mathrm{~h}$, the bands were detected using MiniChemi ${ }^{\mathrm{TM}}$ Chemiluminescence imaging.

Wound healing assay. Following transfection, U87MG cells were seeded in culture plates. A linear wound was made using a micropipette-like tip to create a cell-free zone. The detached cells were 
Table I. Primer sequences for $q R T-P C R$ reactions.

\begin{tabular}{lll}
\hline Gene & Forward & Reverse \\
\hline E-cadherin & GCTGGACCGAGAGAGTTTCC & CAAAATCCAAGCCCGTGGTG \\
BATF2 & GGAATTTGGTGGGTGCCTCTA & GAGACTCGTGCTGCTGGGATA \\
$\beta$-catenin & GAAACGGCTTTCAGTTGAG & CTGGCCATATCCACCAGAGT \\
Vimentin & GAACGCCAGATGCGTGAAATG & CCAGAGGGAGTGAATCCAGATTA \\
N-cadherin & CAACTTGCCAGAAAACTCAGG & ATGAAACCGGGCTATCTGCTC \\
CCN1 & CCAGTGTACAGCAGCCTAAA & CTGGAGCATCCTGCATAAGTAA \\
Twist & CCGGAGACCTAGATGTCATTGTT & CCACGCCCTGTTTCTTTGAAT \\
ZEB1 & AAGAATTCACAGTGGAGAGAAGCCA & CGTTTCTTGCAGTTTGGGCATT \\
Slug & TGCGATGCCCAGTCTAGAAAA & TTCTCCCCCGTGTGAGTCTA \\
$\beta$-actin & GGAAATCGTGCGTGACATTA & TGCGGATGTCCACGTCACAC \\
\hline
\end{tabular}

washed away with PBS. The cell-free area was marked and serum-free medium with or without BV was added. The cells continued to grow in the incubator for an additional 24-48 h. Images were acquired at different time points and the wound was evaluated using ImageJ.

Transwell assay. Costar 24-well transwell plates with $8 \mu \mathrm{m}$-pore were used. The inserts were coated with Matrigel (BD Biosciences) at a concentration of 1:10. U87MG cells of $1 \times 10^{5}$ were plated to a culture insert in serum-free medium with $0-100 \mu \mathrm{g} / \mathrm{mL} \mathrm{BV}$. The serum containing medium was applied to the lower compartment. After incubation for $24 \mathrm{~h}$, the adherent cells at the undersurface were fixed with $4 \%$ paraformaldehyde and then stained with $1 \%$ crystal violet. The air-dried filters were imaged under a microscope.

The ECIS assay. The electric cell substrate impedance sensing (ECIS) system was used for detecting the adhesion and migration of U87MG cells. U87MG cells were transfected and seeded in 8well chambers (8W1E PET; Applied BioPhysics, NY, USA). The impedance was continuously recorded automatically. A current pulse $(3,000 \mathrm{~mA}, 60,000 \mathrm{~Hz}$ for $40 \mathrm{~s})$ was applied at the central area to induce a controlled lesion area within the adhered cells at $5 \mathrm{~h}$. The recovery of electrical impedance was monitored and recorded during the healing process.

\section{Results}

Bevacizumab induced EMT in U87MG glioblastoma cells. We first conducted a series of experiments to determine whether bevacizumab was able to induce EMT in cultured glioma cells. As increased invasion and migration could be typical outcomes of the EMT process, wound healing and Trans-Well assays were performed for the evaluation of cell migration in BV-treated U87MG cells. Following BV treatments under different concentrations, increased cell migration was detected (Figure $1 \mathrm{~A}$ and B) at 24 or $48 \mathrm{~h}$ in wound healing assays, which was confirmed by the Transwell experiments (Figure 1C and D). To verify whether the observed increment in cell mobility was a consequence following the activation of EMT, we detected the expression of various classical EMT marker genes at mRNA or protein levels. Following BV treatment, decreased E-cadherin and increased vimentin or $\mathrm{N}$-cadherin at the mRNA levels were detected. A secretory integrin-binding protein, CCN1, was increased which has been reported to regulate angiogenesis, cell adhesion, migration, proliferation, survival and apoptosis. The expression of EMT related transcription factors including Slug, Twist and ZEB were also increased (Figure 1E). Furthermore, the protein expression of $\mathrm{N}$ cadherin, Vimentin and other EMT related factors were demonstrated to be consistent with the alteration of mRNA (Figure 1F). These data indicated that BV treatments in U87MG cells induced EMT and caused an up-regulation in the ability of cells to invade and migrate.

Bevacizumab treatment activated Wnt/ $\beta$ catenin signaling in U87MG cells. Since Wnt/ $\beta$-catenin signaling played a crucial role in EMT, especially in epithelial tumors, it is important to learn whether $\mathrm{BV}$-induced EMT involved the activation of $\mathrm{Wnt} / \beta$-catenin signaling. TOP/FOP flash luciferase reporter system for $\mathrm{Wnt} / \beta$-catenin downstream TCF/LEF ( $\mathrm{T}$ cell factor/lymphoid enhancer factor) transcription activity was used to measure $\mathrm{Wnt} / \beta$-catenin functions. Lithium chloride $(\mathrm{LiCl})$, as a specific inhibitor for GSK-3 $\beta$ was used as an experimental control. Elevated reporter activities were observed following BV treatment, suggesting that activation of $\mathrm{Wnt} / / \beta$-catenin signaling was possibly required for EMT in U87MG cells (Figure 2A). The expression of $\beta$-catenin was increased at both the mRNA and protein levels (Figure $2 \mathrm{~B}$ and $\mathrm{C}$ ). Since the transcriptional activity of $\beta$-catenin required its translocation from the cytoplasm to the nucleus, we performed immunofluorescence assays to evaluate the distribution pattern of $\beta$-catenin (Figure 2D), which, however, did not show a visual difference.

BATF2 overexpression suppresses Wnt/ $\beta$ catenin signaling. Previous work has shown that BATF2 overexpression could suppress the activation of Wnt signaling (25), which was in 


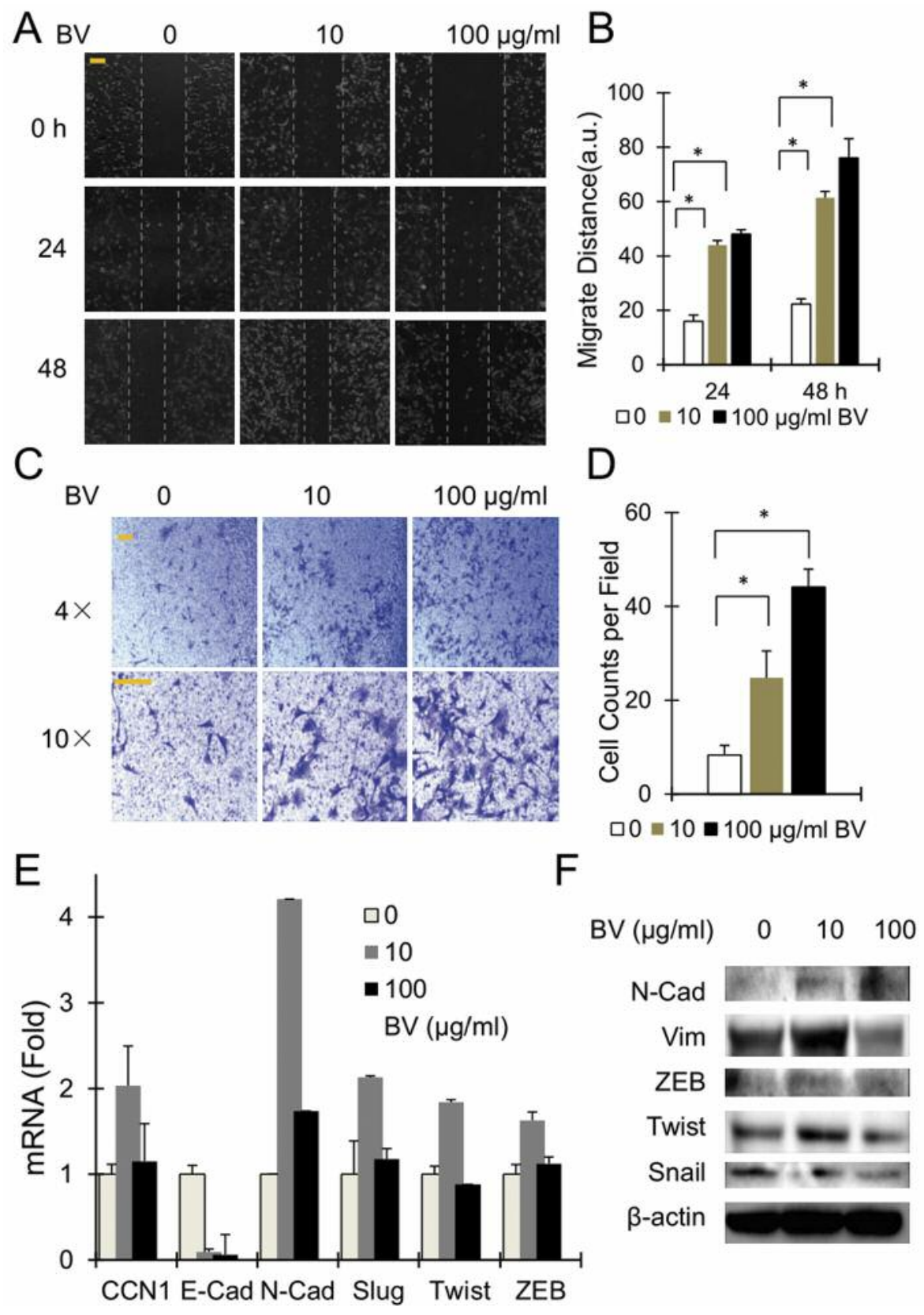

Figure 1. Bevacizumab induced EMT in U87MG glioblastoma cells. (A) Cell migration from wound healing assays in U87MG cells treated with bevacizumab $(0-100 \mu \mathrm{g} / \mathrm{ml})$ for $24 \mathrm{~h}$. Bar $=200 \mu \mathrm{m}$. (B) Quantitative analysis of (A) by ImageJ. ${ }^{*} p<0.05$. (C) Microscopic views from Transwell assays to estimate U87MG cell invasion following $24 \mathrm{~h}$ bevacizumab treatments. Bar $=100 \mu \mathrm{m}$. (D) Quantitative analysis of (A) by ImageJ. * $<<0.05$. (E) RT-PCR quantification of the expression of EMT associated genes using the levels of $\beta$-actin for normalization. $(F)$ Western blot analyses for EMT marker proteins from U87MG treated with bevacizumab.

agreement with the data from our experiments using the Top/Fop reporter system. Overexpression of BATF2 decreased the transcriptional activity of TCF/LEF, indicating inhibition of $\mathrm{Wnt} / \beta$-catenin signaling (Figure $3 \mathrm{~A}$ ). It was interesting to note that the BATF2 suppression on Wnt signaling appeared to be dose dependent, and could be more significant under conditions of increased $\beta$-catenin levels (Figure 3B). To detect whether BATF2 overexpression has a direct role in regulating $\beta$-catenin expression, immunofluorescence was used to stain U87MG cells prior to transfection with the Flag-tagged BATF2 expressive construct. A reduced staining of $\beta$-catenin was observed 


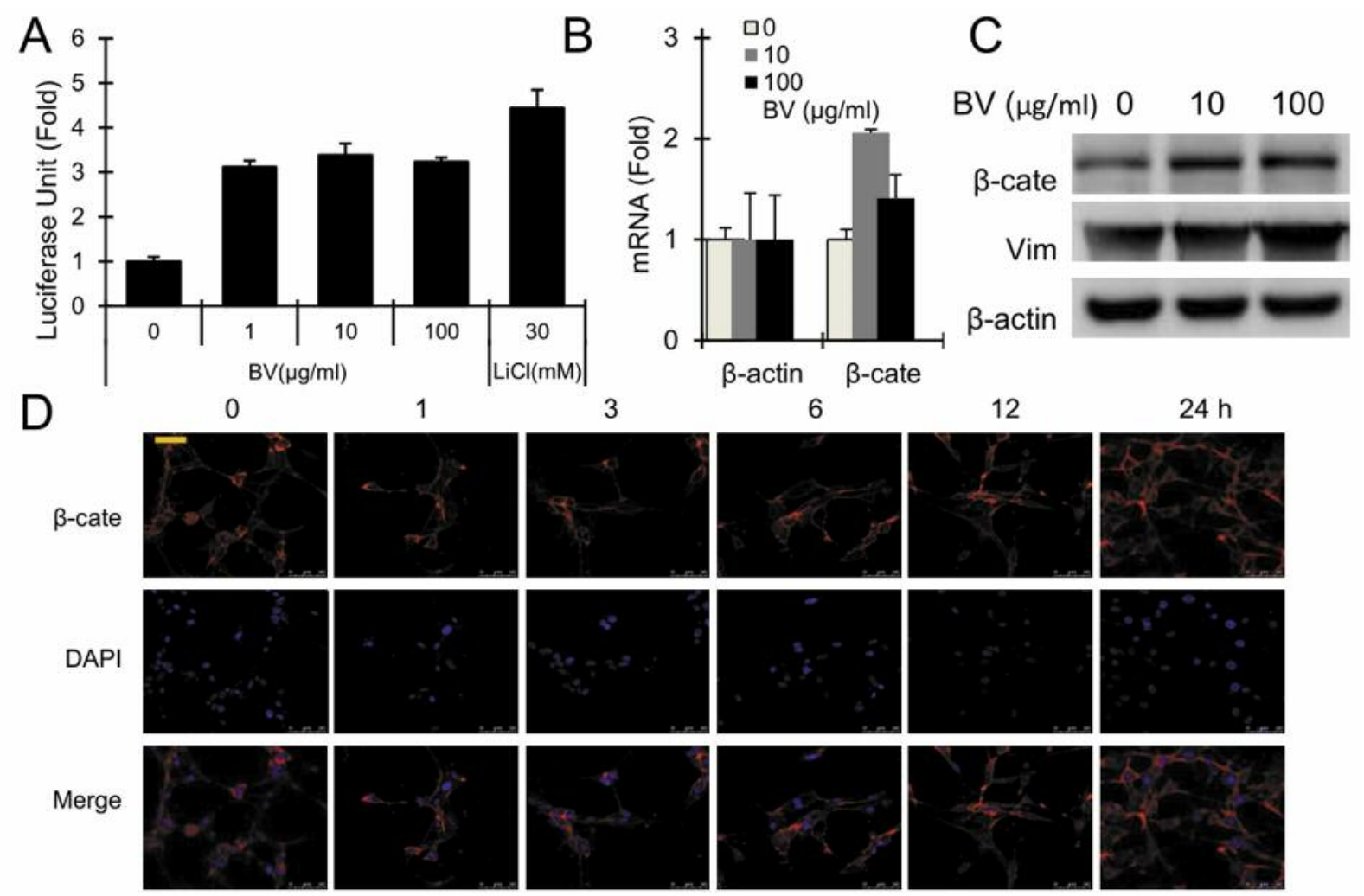

Figure 2. Bevacizumab treatments activated Wnt/ $\beta$-catenin signaling in U87MG cells. (A) TOP/FOP ratio in U87MG treated for 24 hith bevacizumab $(0-100 \mu \mathrm{g} / \mathrm{ml})$ or $\mathrm{LiCl}$. (B) RT-PCR quantification of the expression of $\beta$-catenin after U87MG treated with bevacizumab using the levels of $\beta$-actin for normalization. (C) Western blot for $\beta$-catenin and vimentin in U87MG cells treated with bevacizumab; $\beta$-actin was used as the loading control. (D) Immunofluorescence analyses of cellular $\beta$-catenin localization in U87MG cells treated with bevacizumab at different time points. Bar $=50 \mu \mathrm{m}$.

within Flag positive cells (Figure 3C). To explore whether $\mathrm{BV}$ treatments or Wnt inhibition could in turn cause changes in native BATF2 expression, the cellular BATF2 protein levels were probed by western blotting. A mild increase in BATF2 expression was detected in BV treated U87MG cells (Figure 3D). The finding was consistent with the immunofluorescence results (Figure 3E).

BATF2 overexpression inhibited BV-induced EMT in U87MG cells. From previous results, it was known that bevacizumab was able to activate $\mathrm{Wnt} / \beta$-catenin signaling and induce EMT in U87MG cells, while BATF2 could have the opposite effect. We, therefore, moved on to evaluate whether BATF2 could suppress BV induced EMT. As shown in Figure 4A, upon BATF2 overexpression, suppressed expression of $\mathrm{N}$ cadherin and Snail were detected, whereas the protein levels of Vimentin, $\beta$-catenin, ZEB and Twist did not change significantly. Wound healing assays showed that BATF2 overexpression inhibited $\mathrm{BV}$-induced $\mathrm{U} 87 \mathrm{MG}$ cell migration (Figure 4B and C). In BATF2 transfected cells treated with
BV for $24 \mathrm{~h}$, the protein levels of $\beta$-catenin, Snail and ZEB1 were significantly repressed compared to the controls (Figure 4D). To avoid any subjective bias in determining the dynamics of cell adhesion and migration, we adopted an objective test using the ECIS system. The results from duplicate samples clearly indicated that BATF2 indeed attenuated migration in U87MG cells under conditions with and without BV treatments (Figure 4E).

\section{Discussion}

Angiogenesis is an important process during cancer development that promotes tumor growth and metastasis. It was believed that a successful strategy for antiangiogenic therapy could significantly improve the outcome of cancer treatment. Bevacizumab (Avastin) was the first approved product of such antiangiogenic agents for clinical applications. When used in glioblastoma patients, BV was demonstrated to be able to improve the patients' progressionfree survival (PFS) and the maintenance of baseline quality 

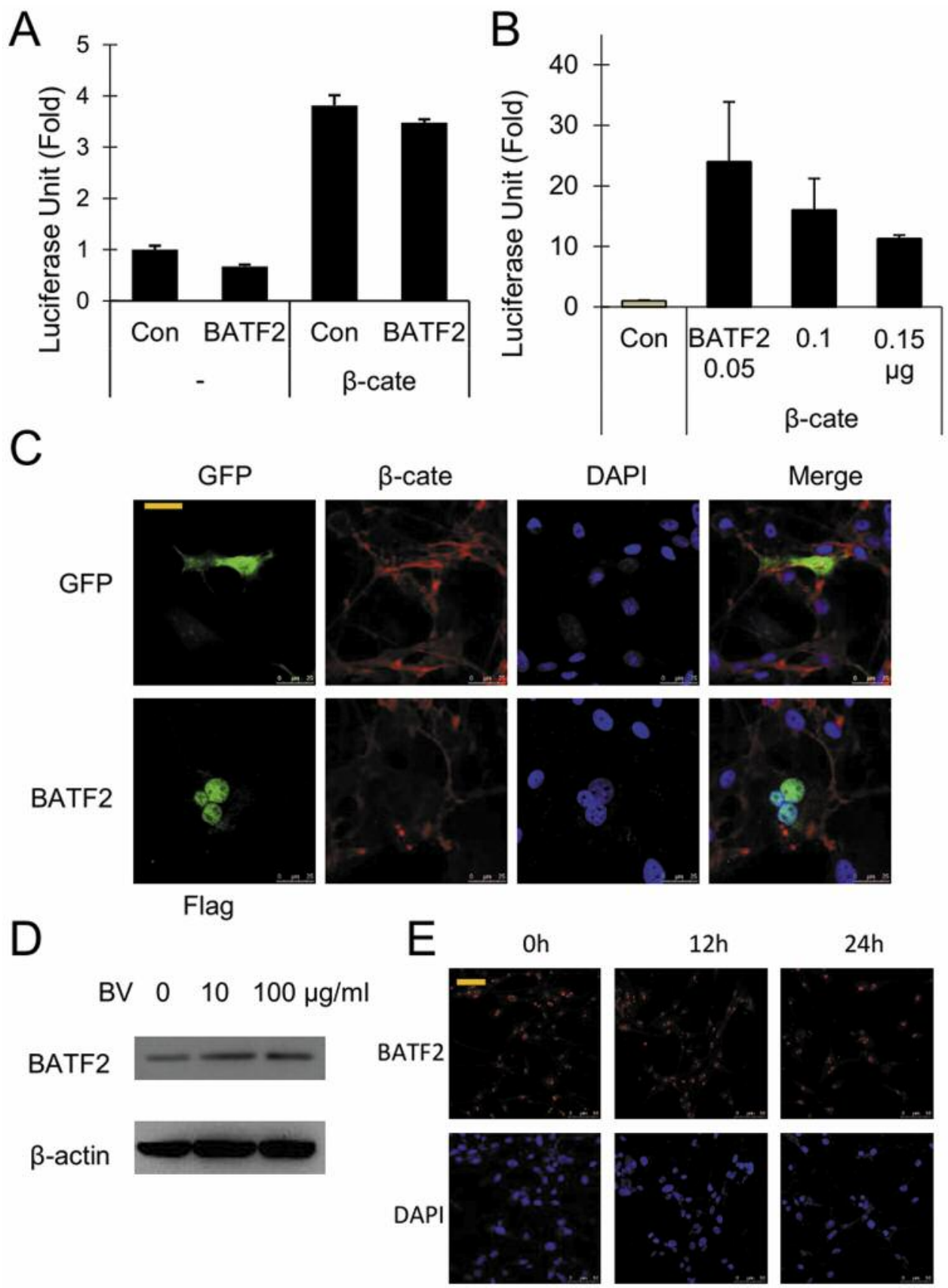

Figure 3. BATF2 overexpression suppress of Wnt/ $\beta$-catenin signaling. (A) Luciferase assays in U87MG cells co-transfected with the Wnt reporter and BATF2 plasmids without/with $\beta$-catenin. (B) The activation of Wnt signaling by TOP/FOP ratio in U87MG cells co-transfected with $\beta$-catenin and increasing amounts of BATF2. (C) Immunofluorescence of the $\beta$-catenin in GTP transfected U87MG cells without/with addition of BATF2. Bar $=50 \mu \mathrm{m}$. (D) BATF2 protein expression levels determined by western blot in U87MG cells treated with bevacizumab $(0-100 \mu \mathrm{g} / \mathrm{ml})$ for $24 \mathrm{~h}$. (E) Immunofluorescence of BATF2 following bevacizumab $100 \mu \mathrm{g} / \mathrm{ml}$ treatment in U87MG at 0 to $24 \mathrm{~h}$. Bar=50 $\mu \mathrm{m}$.

of life $(2,27)$. Meanwhile, the lack of evidence for the improvement in overall survival (OS) benefit suggested the progression of tumors might not be stalled as expected. Moreover, high incidence of adverse events were observed
$(28,29)$, mostly due to the side effects of bevacizumab in glioma patients (30). The recent discovery of BV-induced EMT has become a critical concern for its clinical application. From laboratory research, it has been found that 

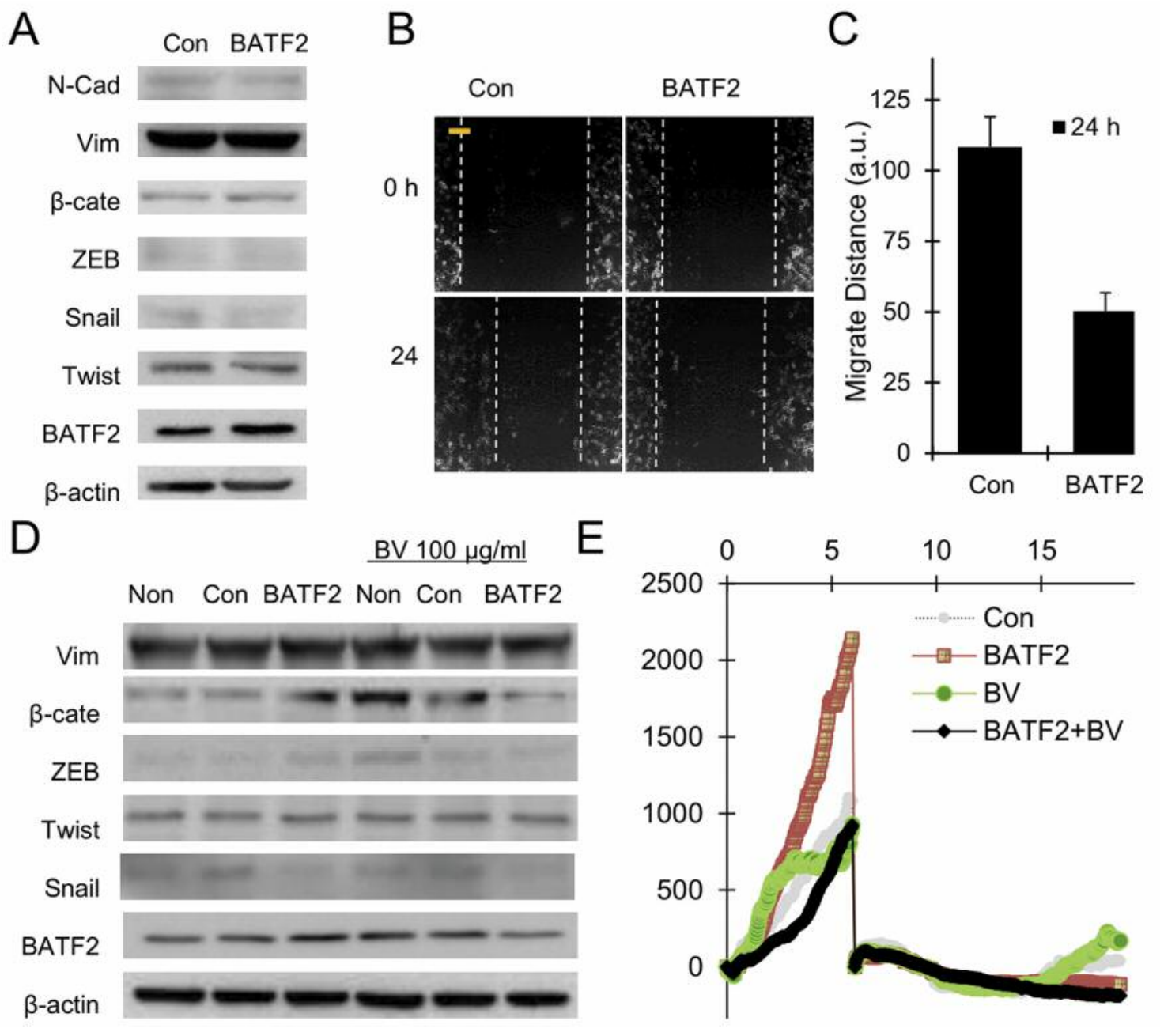

Figure 4. BATF2 overexpression inhibited BV-induced EMT in U87MG cells. (A) Western blot analyses for EMT marker proteins in BATF2transfected cells. (B) Cell migration from wound healing assays in U87MG cells transfected with BATF2 without/with the presence of $100 \mu \mathrm{g} / \mathrm{ml}$ bevacizumab for $24 \mathrm{~h}$. Bar=200 $\mu \mathrm{m}$. (C) Quantitative analysis of (B) using ImageJ. (D) Immunoblots of EMT marker proteins wo/w $100 \mu \mathrm{g} / \mathrm{ml}$ bevacizumab treatments in control or BATF2 transfected cells. (E) ECIS assays for dynamic cell adhesion and migration measures in U87MG cells transfected with a BATF2 $w /$ wo the exposure of $100 \mu \mathrm{g} / \mathrm{ml}$ bevacizumab for $24 \mathrm{~h}$; a current pulse was applied at $6 \mathrm{~h}$.

glioblastoma tumors could avoid antiangiogenic treatment by reactivating angiogenesis and invading normal brain areas through up-regulation of matrix metalloproteinases MMP-2, MMP-9 and MMP-12 (31). VEGF ablation in GBM mouse models was demonstrated to lead to the blockage of EMT with tumor invasion (32). Subsequent studies showed that the anti-angiogenic efficacy in gliomas seemed to require the normal activity of ZEB2, a family member of the zinc finger E-box binding homeobox genes (33). To better understand the potential mechanisms for the cause of $\mathrm{BV}$-induced adverse effects, a number of hypotheses were tested, including the observed upregulation of hypoxia-inducible factors (HIFs) related to tumor progression and metastasis (34), particularly in gliomas $(13,35)$. More recently, the importance of the
Wnt/ $\beta$-catenin signaling pathway in EMT regulation has been demonstrated in a variety of tumor types (36-38). The activation of $\mathrm{Wnt} / \beta$-catenin signaling was reported to sufficiently induce EMT in glioma cells (39), however, its role in the BV-induced EMT process has not been investigated. In this study, when we treated U87MG cells with various concentrations of bevacizumab, EMT activation was indeed observed. As expected, the activation of $\mathrm{Wnt} / / \beta$ catenin signaling was detected to associate with $\mathrm{BV}$-induced EMT development. To our surprise, we did not observe a significant increase in $\beta$-catenin nuclear translocation. This seemed to suggest that the mechanism of BV-induced Wnt activation could be more complex than previously hypothesized. This could possibly involve the reduced 
cellular degradation of $\beta$-catenin proteins, which could lead to crippled $\beta$-catenin mobilization to the nucleus; or, the activation of certain non-canonical signals which would not require $\beta$-catenin for its nuclear translocation $(40,41)$.

BATF2 was initially discovered as a potential tumor suppressor which was able to inhibit the growth of various cancer cells $(17,22,42)$. It was found to directly repress the activity of AP-1, which serves as an essential transcription factor for cell proliferation and oncogenic transformation (17). Recently, BATF2 was demonstrated to suppress cell migration via the inhibition of the $\mathrm{Wnt} / \beta$-catenin pathway in lung adenocarcinoma cells (25). This prompted the possibility that BATF2 could inhibit the activation of EMT. Nevertheless, research about the biological functions and the related mechanism of BATF2 was relatively insufficient. We first investigated whether BATF2 overexpression was able to suppress Wnt/ $\beta$-catenin signaling and inhibit the progression of EMT in glioblastoma cells. The results showed a potent effect which seemed to be consistent with what was found in lung adenocarcinomas (25). We further examined the connection of BATF2 overexpression with EMT makers and cell migration behavior following BV treatment. We were able to demonstrate that the temporal overdose of BATF2 expression via transient transfection, significantly suppressed the development of EMT in U87MG cells. However, the inhibitory effect did not seem to require the long-term maintenance of a high BATF2 level. In fact, when EMT was suppressed following BATF2 overexpression, the endogenous BATF2 levels appeared to be downregulated. This was strikingly different to the situation of BV exposure alone, where the cellular protein level of BATF2 was increased. A possible explanation to these intriguing results could be that an additional mechanism, other than BATF2 inhibition on Wnt signaling, was also involved and responsible for the suppression of EMT in glioma cells. As a potent transcription regulator, BATF2 was suggested to have numerous potential targets (43). It would not be surprising if certain BATF2 responsive genes indirectly impacted or were engaged in crosstalk with the Wnt signal molecules. As suggested from recent reports, the transcription factor HIF-1 mediated responses in glioma cells could be considered as an important mechanism for BATF2 inhibition on EMT progression $(13,35)$.

The critical role of hypoxia for the induction of EMT phenotypes accompanied with up-regulated $\beta$-catenin expression has been identified in various tumors $(44,45)$. The interconnection between $\mathrm{Wnt} / \beta$-catenin signaling and hypoxia response appeared to be intricate. The $\mathrm{Wnt} / \beta$ catenin activation enhanced hypoxia-induced EMT under certain circumstances (46). In embryonic stem (ES) cells (47) or glioma cells following BV treatment, it was believed that the hypoxic microenvironment was able to trigger a set of signaling molecules to promote the development of EMT, including Wnt $/ \beta$-catenin (16), which might or might not be regulated by HIF- $1 \alpha$. Our findings provided additional evidence suggesting that BATF2 overexpression was sufficient to inhibit BV-induced EMT with a suppressive effect on Wnt/ $\beta$-catenin signaling. The latest studies have shown that BATF2 inhibits the activity of the HIF-1a/VEGF axis (24). This emphasized a potential application for BATF2 being used as a potent molecule to suppress EMT, especially under hypoxic conditions. At this point, it is still undetermined as to whether the inhibition of BATF2 overexpression on HIF and Wnt signaling acts independently or through crosstalk. From our results, overexpression of BATF2 did not affect $\beta$-catenin nuclear transportation, but on the other hand, dose dependently correlated to $\beta$-catenin expression levels (Figures 3 and 4) strongly suggested a mechanism of coordination involving both Wnt and HIF mediated signaling pathways. Thus, although BATF2 can be used as a therapeutic candidate for cancer gene therapy with a compensatory effect that counteracts the adverse effect of BV treatments, the exact signaling path and targeted genes remained elusive (43), and the complexity of the underlining mechanisms demands further in depth investigation.

\section{Conflicts of Interest}

The Authors declare no conflicts of interest.

\section{Acknowledgements}

This study was supported by Chinese Natural Science Foundation projects \#31201032 and \#81372284.

\section{References}

1 Malzkorn B and Reifenberger G: Practical implications of integrated glioma classification according to the World Health Organization classification of tumors of the central nervous system. Curr Opin Oncol 28(6): 494-501, 2016.

2 Stupp R, Mason WP, van den Bent MJ, Weller M, Fisher B, Taphoorn MJ, Belanger K, Brandes AA, Marosi C, Bogdahn U, Curschmann J, Janzer RC, Ludwin SK, Gorlia T, Allgeier A, Lacombe D, Cairncross JG, Eisenhauer E and Mirimanoff RO: Radiotherapy plus concomitant and adjuvant temozolomide for glioblastoma. N Engl J Med 352(10): 987-996, 2005.

3 Yung WK, Albright RE, Olson J, Fredericks R, Fink K, Prados MD, Brada M, Spence A, Hohl RJ, Shapiro W, Glantz M, Greenberg H, Selker RG, Vick NA, Rampling R, Friedman H, Phillips P, Bruner J, Yue N, Osoba D, Zaknoen S and Levin VA: A phase II study of temozolomide vs. procarbazine in patients with glioblastoma multiforme at first relapse. Br J Cancer 83(5): 588-593, 2000.

4 Friedman HS, Prados MD, Wen PY, Mikkelsen T, Schiff D, Abrey LE, Yung WK, Paleologos N, Nicholas MK, Jensen R, Vredenburgh J, Huang $J$, Zheng $M$ and Cloughesy $T$ : Bevacizumab alone and in combination with irinotecan in recurrent glioblastoma. J Clin Oncol 27(28): 4733-4740, 2009. 
5 Kreisl TN, Kim L, Moore K, Duic P, Royce C, Stroud I, Garren N, Mackey M, Butman JA, Camphausen K, Park J, Albert PS and Fine HA: Phase II trial of single-agent bevacizumab followed by bevacizumab plus irinotecan at tumor progression in recurrent glioblastoma. J Clin Oncol 27(5): 740-745, 2009.

6 Vredenburgh JJ, Desjardins A, Herndon JN, Dowell JM, Reardon DA, Quinn JA, Rich JN, Sathornsumetee S, Gururangan S, Wagner M, Bigner DD, Friedman AH and Friedman HS: Phase II trial of bevacizumab and irinotecan in recurrent malignant glioma. Clin Cancer Res 13(4): 1253-1259, 2007.

7 Cohen MH, Shen YL, Keegan P and Pazdur R: FDA drug approval summary: bevacizumab (Avastin) as treatment of recurrent glioblastoma multiforme. Oncologist 14(11): 1131-1138, 2009.

8 Kahlert UD, Nikkhah G and Maciaczyk J: Epithelial-tomesenchymal (-like) transition as a relevant molecular event in malignant gliomas. Cancer Lett 331(2): 131-138, 2013.

9 Yang J and Weinberg RA: Epithelial-mesenchymal transition: at the crossroads of development and tumor metastasis. Dev Cell 14(6): 818-829, 2008.

10 Polyak K and Weinberg RA: Transitions between epithelial and mesenchymal states: acquisition of malignant and stem cell traits. Nat Rev Cancer 9(4): 265-273, 2009.

11 Iwadate Y: Epithelial-mesenchymal transition in glioblastoma progression. Oncol Lett 11(3): 1615-1620, 2016.

12 Bergers $G$ and Hanahan D: Modes of resistance to antiangiogenic therapy. Nat Rev Cancer 8(8): 592-603, 2008.

$13 \mathrm{Xu} \mathrm{H}$, Rahimpour S, Nesvick CL, Zhang X, Ma J, Zhang M, Zhang G, Wang L, Yang C, Hong CS, Germanwala AV, Elder JB, Ray-Chaudhury A, Yao Y, Gilbert MR, Lonser RR, Heiss JD, Brady RO, Mao Y, Qin J and Zhuang Z: Activation of hypoxia signaling induces phenotypic transformation of glioma cells: implications for bevacizumab antiangiogenic therapy. Oncotarget 6(14): 11882-11893, 2015.

14 MacDonald BT, Tamai K and He X: Wnt/beta-catenin signaling: components, mechanisms, and diseases. Dev Cell 17(1): 9-26, 2009.

15 Klaus A and Birchmeier W: Wnt signalling and its impact on development and cancer. Nat Rev Cancer 8(5): 387-398, 2008.

16 Valenta T, Hausmann $\mathrm{G}$ and Basler $\mathrm{K}$ : The many faces and functions of beta-catenin. EMBO J 31(12): 2714-2736, 2012.

17 Su ZZ, Lee SG, Emdad L, Lebdeva IV, Gupta P, Valerie K, Sarkar D and Fisher PB: Cloning and characterization of SARI (suppressor of AP-1, regulated by IFN). Proc Natl Acad Sci USA 105(52): 20906-20911, 2008.

18 Liu Z, Wei P, Yang Y, Cui W, Cao B, Tan C, Yu B, Bi R, Xia K, Chen W, Wang Y, Zhang Y, Du X and Zhou X: BATF2 Deficiency Promotes Progression in Human Colorectal Cancer via Activation of HGF/MET Signaling: A Potential Rationale for Combining MET Inhibitors with IFNs. Clin Cancer Res 21(7): 1752-1763, 2015.

19 Wen H, Chen Y, Hu Z, Mo Q, Tang J and Sun C: Decreased expression of BATF2 is significantly associated with poor prognosis in oral tongue squamous cell carcinoma. Oncol Rep 31(1): 169-174, 2014.

20 Ma H, Liang X, Chen Y, Pan K, Sun J, Wang H, Wang Q, Li Y, Zhao J, Li J, Chen M and Xia J: Decreased expression of BATF2 is associated with a poor prognosis in hepatocellular carcinoma. Int J Cancer 128(4): 771-777, 2011.

21 Guler R, Roy S, Suzuki H and Brombacher F: Targeting Batf2 for infectious diseases and cancer. Oncotarget 6(29): 2657526582, 2015.
22 Dash R, Su ZZ, Lee SG, Azab B, Boukerche H, Sarkar D and Fisher PB: Inhibition of AP-1 by SARI negatively regulates transformation progression mediated by $\mathrm{CCN} 1$. Oncogene 29(31): 4412-4423, 2010.

$23 \mathrm{Lu} \mathrm{Z}$, Zheng SP, Niu J, Jia HT and Ding W: BATF2/SARI induces tumor cell apoptosis by inhibiting p53-dependent NF$\mathrm{kB}$ activity, Chinese Journal of Biochemistry and Molecular Biology 27(9): 524-532, 2011.

24 Dai L, Cui X, Zhang X, Cheng L, Liu Y, Yang Y, Fan P, Wang Q, Lin Y, Zhang J, Li C, Mao Y, Wang Q, Su X, Zhang S, Peng Y, Yang H, Hu X, Yang J, Huang M, Xiang R, Yu D, Zhou Z, Wei $Y$ and Deng H: SARI inhibits angiogenesis and tumour growth of human colon cancer through directly targeting ceruloplasmin. Nat Commun 7: 11996, 2016.

25 Wang C, Su Y, Zhang L, Wang M, You J, Zhao X, Zhang Z, Liu $\mathrm{J}$ and Hao X: The function of SARI in modulating epithelialmesenchymal transition and lung adenocarcinoma metastasis. PLoS One 7(9): e38046, 2012.

26 Mesti T, Savarin P, Triba MN, Le Moyec L, Ocvirk J, Banissi C and Carpentier AF: Metabolic impact of anti-angiogenic agents on U87 glioma cells. PLoS One 9(6): e99198, 2014.

27 Narayana A, Kelly P, Golfinos J, Parker E, Johnson G, Knopp E, Zagzag D, Fischer I, Raza S, Medabalmi P, Eagan P and Gruber ML: Antiangiogenic therapy using bevacizumab in recurrent high-grade glioma: impact on local control and patient survival. J Neurosurg 110(1): 173-180, 2009.

28 Chinot OL, Nishikawa R, Mason W, Henriksson R, Saran F, Cloughesy T, Garcia J, Revil C, Abrey L and Wick W: Upfront bevacizumab may extend survival for glioblastoma patients who do not receive second-line therapy: an exploratory analysis of AVAglio. Neuro Oncol 18(9): 1313-1318, 2016.

29 Gilbert MR, Dignam JJ, Armstrong TS, Wefel JS, Blumenthal DT, Vogelbaum MA, Colman H, Chakravarti A, Pugh S, Won M, Jeraj R, Brown PD, Jaeckle KA, Schiff D, Stieber VW, Brachman DG, Werner-Wasik M, Tremont-Lukats IW, Sulman EP, Aldape KD, Curran WJ and Mehta MP: A randomized trial of bevacizumab for newly diagnosed glioblastoma. N Engl J Med 370(8): 699-708, 2014.

30 Bumes E, Rzonsa S, Hutterer M, Proescholdt M, Bogdahn U, Riemenschneider MJ, Uhl M, Wendl $\mathrm{C}$ and Hau P: Adverse event grading following CTCAE v3.0 underestimates hypertensive side effects in patients with glioma treated with Bevacizumab. J Neurooncol 127(1): 191-200, 2016.

31 Lucio-Eterovic AK, Piao Y and de Groot JF: Mediators of glioblastoma resistance and invasion during antivascular endothelial growth factor therapy. Clin Cancer Res 15(14): 45894599, 2009.

32 Lu KV, Chang JP, Parachoniak CA, Pandika MM, Aghi MK, Meyronet D, Isachenko N, Fouse SD, Phillips JJ, Cheresh DA, Park $\mathrm{M}$ and Bergers G: VEGF inhibits tumor cell invasion and mesenchymal transition through a MET/VEGFR2 complex. Cancer Cell 22(1): 21-35, 2012.

33 Depner C, Zum BH, Bogurcu N, Cuesta AM, Aburto MR, Seidel S, Finkelmeier F, Foss F, Hofmann J, Kaulich K, Barbus S, Segarra M, Reifenberger G, Garvalov BK, Acker T and AckerPalmer A: EphrinB2 repression through ZEB2 mediates tumour invasion and anti-angiogenic resistance. Nat Commun 7: 12329, 2016.

34 Blagosklonny MV: Antiangiogenic therapy and tumor progression. Cancer Cell 5(1): 13-17, 2004. 
35 Piao Y, Liang J, Holmes L, Henry V, Sulman E and de Groot JF: Acquired resistance to anti-VEGF therapy in glioblastoma is associated with a mesenchymal transition. Clin Cancer Res 19(16): 4392-4403, 2013.

36 Hwang I, Kim J and Jeong S: beta-Catenin and peroxisome proliferator-activated receptor-delta coordinate dynamic chromatin loops for the transcription of vascular endothelial growth factor A gene in colon cancer cells. J Biol Chem 287(49): 41364-41373, 2012.

37 Watcharasit P, Suntararuks S, Visitnonthachai D, Thiantanawat $\mathrm{A}$ and Satayavivad J: beta-catenin involvement in arseniteinduced VEGF expression in neuroblastoma SH-SY5Y cells. Environ Toxicol 29(6): 672-678, 2014.

38 Mottet D, Dumont V, Deccache Y, Demazy C, Ninane N, Raes M and Michiels C: Regulation of hypoxia-inducible factor-1alpha protein level during hypoxic conditions by the phosphatidylinositol 3-kinase/Akt/glycogen synthase kinase 3beta pathway in HepG2 cells. J Biol Chem 278(33): 31277-31285, 2003.

39 Zhang L, Liu H, Mu X, Cui J and Peng Z: Dysregulation of Fra1 expression by $\mathrm{Wnt} /$ beta-catenin signaling promotes glioma aggressiveness through epithelial-mesenchymal transition. Biosci Rep 37(2): 2017.

40 Seifert JR and Mlodzik M: Frizzled/PCP signalling: a conserved mechanism regulating cell polarity and directed motility. Nat Rev Genet 8(2): 126-138, 2007.

41 Wang Y and Nathans J: Tissue/planar cell polarity in vertebrates: new insights and new questions. Development 134(4): 647-658, 2007.

42 Zhou RJ, Shi Z, Zhou K, Wang HD, Zhang GQ, Li XT and Xu JP: Decreased SARI expression predicts poor prognosis of Chinese patients with non-small cell lung cancer. Int J Clin Exp Pathol 6(10): 2056-2063, 2013.
43 Bai X, Huang W, Zhang C, Niu J and Ding W: Discovery of a regulatory motif for human satellite DNA transcription in response to BATF2 overexpression. Anticancer Res 36(3): 12031210, 2016.

$44 \mathrm{Xu}$ W, Zhou W, Cheng M, Wang J, Liu Z, He S, Luo X, Huang W, Chen T, Yan W and Xiao J: Hypoxia activates Wnt/betacatenin signaling by regulating the expression of BCL9 in human hepatocellular carcinoma. Sci Rep 7: 40446, 2017.

45 Lee SY, Jeong EK, Ju MK, Jeon HM, Kim MY, Kim CH, Park HG, Han SI and Kang HS: Induction of metastasis, cancer stem cell phenotype, and oncogenic metabolism in cancer cells by ionizing radiation. Mol Cancer 16(1): 10, 2017.

46 Zhang Q, Bai X, Chen W, Ma T, Hu Q, Liang C, Xie S, Chen $\mathrm{C}, \mathrm{Hu} \mathrm{L}, \mathrm{Xu} \mathrm{S}$ and Liang T: Wnt/beta-catenin signaling enhances hypoxia-induced epithelial-mesenchymal transition in hepatocellular carcinoma via crosstalk with hif-1alpha signaling. Carcinogenesis 34(5): 962-973, 2013.

47 Mazumdar J, O’Brien WT, Johnson RS, LaManna JC, Chavez JC, Klein PS and Simon MC: O2 regulates stem cells through Wnt/beta-catenin signalling. Nat Cell Biol 12(10): 1007-1013, 2010 . 